\title{
Systemic Lupus Erythematosus: some Epidemiological and Clinical Aspects
}

\author{
Angel Justiz-Vaillant ${ }^{1, *}$, Patrick E. Akpaka1, Peter Poonking ${ }^{2}$ \\ ${ }^{1}$ Department of Paraclinical Sciences, The University of the West Indies, St. Augustine, Trinidad and Tobago \\ ${ }^{2}$ San Fernando General Hospital, San Fernando, Trinidad and Tobago \\ *Corresponding author: Angel.Vaillant@sta.uwi.edu
}

Received January 29, 2015; Revised February 20, 2015; Accepted March 01, 2015

\begin{abstract}
Systemic lupus erythematosus (SLE) is a complex autoimmune disorder with a wide array of clinical manifestations including rash, photosensitivity, oral ulcers, arthritis, serositis, glomerulonephritis among others clinical findings. In this paper we globally summarized the most important epidemiological and clinical aspects to bear in mind, when the time comes to make the diagnosis of this rheumatic disorder and its management. Factor that are involved in the SLE pathogenesis and novel treatment options are mentioned.
\end{abstract}

Keywords: systemic lupus erythematosus, epidemiology, prevalence, incidence, mortality, immunology

Cite This Article: Angel Justiz-Vaillant, Patrick E. Akpaka, and Peter Poonking, "Systemic Lupus Erythematosus: some Epidemiological and Clinical Aspects.” American Journal of Public Health Research, vol. 3, no. 2 (2015): 46-50. doi: 10.12691/ajphr-3-2-2.

\section{Introduction}

Systemic lupus erythematosus (SLE) is a complex autoimmune disorder which develops in genetically prone individuals under the influence of various environmental factors. It is a prototypical autoimmune disease with a wide array of clinical manifestations (rash, photosensitivity, oral ulcers, arthritis, pleuritis, pericarditis, kidney problems, seizures and psychosis, blood cell abnormalities). It is characterized by the production of antibodies to components of the cell nucleus [1,2]. Primarily a disease of young women; occurs from infancy to old age, with peak occurrence between ages 15 and 40 . Females are affected far more than males (6-10:1); and blacks (and possibly Hispanics, Asians, and Native Americans) are affected more than whites [1,2].

Although there is a strong familial aggregation, the disease is relatively uncommon and most cases are sporadic. The condition may occur with other autoimmune conditions (e.g., thyroiditis, haemolytic anaemia, idiopathic thrombocytopenia purpura) [1,2]. Diagnosis can be very difficult. The gold standard is a rheumatologist's diagnosis. The American College of Rheumatology (ACR) uses a standard classification scheme requiring 4 of 11 criteria for research definition, although this is recognized to miss early and mild cases. Even so, there is under diagnosis because the presenting symptoms and signs are often not specific; and over diagnosis because doctors mistakenly use a positive blood test (present in 5\% of the healthy population) by itself to make a diagnosis [1,2].

Accelerated atherosclerosis among these patients is a newly recognized phenomenon responsible for premature mortality. Treatment consists primarily of immunosuppressive drugs (e.g., hydroxyl chloroquine [Plaquenil] and corticosteroids [prednisone]). In 2011 the FDA approved the first new drug for lupus in more than 50 years-belimumab [BENLYSTA $®$ ]. Morbidity and mortality may be related to late diagnosis, problems in access to care, less effective treatments, and poor compliance with therapeutic regimens [1,2].

\section{Prevalence}

Prevalence estimates vary widely, and range as high as 1,500,000 (Lupus Foundation of America) [3]. A recent study estimated a 2005 prevalence of 161,000 with definite SLE and 322,000 with definite or probable SLE [4]. In the USA, Congress has funded CDC to conduct two population-based SLE registries with the primary purpose of generating better prevalence (and incidence) estimates for Caucasians and African Americans. One is in Michigan (Washtenaw and Wayne Counties) and the other is in Georgia (DeKalb and Fulton Counties). New registries in California (San Francisco and San Mateo Counties) and New York City (Manhattan) are funded to generate similar estimates for Hispanics and Asians. The Indian Health Service is developing similar estimates for American Indians/Alaska Natives [3,4].

The reported prevalence of systemic lupus erythematosus (SLE) in the population is 20 to 150 cases per 100,000 [5,6,7]. In women, prevalence rates vary from 164 (white) to 406 (African American) per 100,000 [6]. Due to improved detection of mild disease, the incidence nearly tripled in the last 40 years of the 20th century [8]. Estimated incidence rates are 1 to 25 per 100,000 in North America, South America, Europe and Asia [7,9,10,11]. Geographic and racial distribution - both geography and 
race affect the prevalence of SLE and of frequency and severity of clinical and laboratory manifestations. The disease appears to be more common in urban than rural areas [6,12]. The prevalence of SLE is higher among Asians, Afro-Americans, Afro-Caribbeans, and Hispanic Americans compared with Americans of European decent in the United States, and among Asian Indians compared with Caucasians in Great Britain [10,13,14].

In comparison, SLE occurs infrequently in Blacks in Africa [15]. In New Zealand, the prevalence and mortality of SLE are higher in Polynesians than in Caucasians [16]. Photosensitivity and discoid skin lesions may be more frequent clinical manifestations in patients with Northern European than those with Southern European ancestry; the former group is, however, less likely to have anticardiolipin and anti-dsDNA antibodies [17].

Gender - the increased frequency of SLE among women has been attributed in part to an estrogen hormonal effect (see 'Hormonal factors' below) [18,19]. An estrogen effect is suggested by a number of observations including the female-to-male ratio of SLE in different age groups: in children, in whom sex hormonal effects are presumably minimal, the female-to-male ratio is 3:1 [20]. In adults, especially in women of child-bearing years, the ratio ranges from 7:1 to $15: 14[6,20]$. In "older" individuals, especially post-menopausal women, the ratio is approximately 8:1 [20].

\subsection{Incidence}

In several places, national incidence data are difficult to obtain because onset is difficult to determine (non-specific symptoms and signs) and the required, resource-intense studies are done in small areas. [21]. Existing estimates range widely, from 1.8 to 7.6 cases per 100,000 persons per year in parts of the continental United States [21]. Incidence rates in whites in Rochester, Minnesota (Mayo Clinic's Rochester Epidemiology Project) tripled from $1.5 / 100,000$ in the $1950-1979$ cohorts to $5.6 / 100,000$ in 1980-1992 cohorts [22].

\subsection{Mortality}

From 1979 to 1998 , the annual number of deaths with lupus as the underlying cause increased from 879 to 1,406 . Crude death rates increased with age (35\% were in 15-44 year age group), among women (5 times higher than in men), and among blacks (3 times higher than in whites). Death rates were highest and increased the most over time among black women aged 45-64 years [23]. An equivalent number listed lupus as a contributing cause of death. Causes of death are mainly active disease, organ failure (e.g., kidneys), infection, or cardiovascular disease from accelerated atherosclerosis. Among rheumatic conditions, lupus has a relatively high mortality (14.5\% of all rheumatic disease mortality in 1997). At the same time, survival has been improving, suggesting that more or milder cases are being recognized [23].

\section{Stress and SLE}

It has been proved that stress worsens clinical signs and symptoms of patients with lupus. It is recommended to lupus patients to reduce the stress. It is based on numerous studies where associations between daily stress and disease exacerbations have been demonstrated [24,25]. It is believed that the higher SLE prevalence seen in AfroAmericans is related to stress factors. They are poverty, high rates of unemployment, incarceration, violent crime, and homicide. They constitute a socio-biological disadvantage that can be accumulated at multiple points during the life of this population [26]. Stress-management programmes in a group of Afro-Americans demonstrated that workshop interventions can be effective in improving clinical signs and symptoms of SLE [25].

\subsection{Perinatal Risk Factors for SLE}

In a SLE study carried out in Sweden were identified 774 cases and 3337 controls; the age at which SLE was first observed ranged from 0 to 36 years old [27]. The high birth weight was not a risk factor for SLE as previously described, where birth weight $>$ or $=10$ pounds was positively associated with SLE among women [27,28]. Males had a 2.4-fold increased odds of SLE if born preterm (<37 weeks; OR = 2.41; 95\% CI 1.09, 5.36). Birth order was significantly associated with SLE, particularly among females. The odds of SLE were increased by $12 \%$ for every additional birth [27]. Being or not breastfed was not associated with SLE [28].

\subsection{Cardiovascular Risk and SLE}

The leading cause of mortality in the SLE patient population is cardiovascular disease at an age when women often have low cardiovascular risk. Hypertension is a major cardiovascular disease risk factor, and its incidence and prevalence are markedly increased in women with SLE [29].

\subsection{The Use of Oral Contraceptives and SLE}

The role of estrogens in SLE development is supported by studies from experimental SLE animal models in which early suppression of estrogens leads to attenuation of SLE disease parameters, including renal injury and autoantibody production [29]. However, in human SLE data about the role of estrogens are inconclusive and much less clear. Rojas-Villarraga et al, 2014 reported that hormonal replacement therapy (HRT) was associated with SLE development. No association was found when analyzing the risk for SLE among oral contraceptive (OC) users [30]. Others studies have reported conflicting results on this matter. There was a group of female affected with SLE in which the use of HRT or OC did not cause SLE exacerbation but in small amounts of SLE patients [31-32]. The fact that the female/male ratio in SLE can be as high as $15: 1$, suggests that environmental factors and hormones play an important role in the SLE immunopathogenesis.

\subsection{Environmental Factors and SLE}

Systemic lupus erythematosus (SLE) is a chronic autoimmune disease in which both genetic and environmental factors are involved. Vitamin D is one such environmental factor that plays a specific function in the immune system, acting through a nuclear receptor (VDR) expressed in all immune cells. Several polymorphisms of the gene that encodes this receptor have been described. Carvalho et al, 2015 reported about a possible role of 
VDR gene polymorphisms in SLE. Between VDR polymorphisms and SLE severity (chronic damage) a positive association was found. The occurrence of CT genotype of FokI seems to confer a worse prognosis in SLE [33]. The SLE etiology is still not fully understood. There is lack of concordance of the disease amongst genetically identical twins suggesting that both genetic and environmental triggers are likely to orchestrate the onset and flares of SLE [34,35].

A list of environmental factors, such as alcohol, ultraviolet light, cigarette smoke, chemicals, infections caused by Epstein Barr virus and parvovirus, hormones, and vaccines, have been linked to SLE development in many populations in case-control studies and several randomized controlled clinical trials [34,35,36,37]. Another environmental factor involved in the SLE immunogenesis is the drugs hydralazine, which is implicated in inhibiting T-cell DNA methylation; diet, and agents causing oxidative stress are also involved in the SLE genesis [38].

\subsection{Genetic Factor and SLE}

Several studies have been performed with TNF- $\alpha-308$ G/A (rs1800629) single nuclear polymorphism (SNP) to evaluate the risk of SLE in various ethnicities. A genetic Polish study indicated that the TNF- $\alpha-308$ G/A polymorphism may be a DRB1*03:01 haplotype, a dependent genetic risk factor for SLE; and concluded that this SNP was independently associated with renal manifestations and production of anti-Ro antibodies [39]. Another genetic study was carried out in European descendent patients and revealed that polymorphisms in STK17A gene are associated with systemic lupus erythematosus and its clinical manifestations, for example the haplotype TAGTC was associated to haematological alterations [40].

\subsection{Immunological Factors and SLE}

Excessive activity of dendritic cells (DCs) is postulated as a central disease mechanism in Systemic Lupus Erythematosus [41], this can be exacerbated by proinflammatory factors, in particular Type I IFNs, which modulate B cell function in lupus causing an alteration of the immunological tolerance [42]. In SLE autoantibodies form immune-complexes that are deposited in several organs and trigger inflammatory reactions followed by tissue damage. These auto-antibodies are meanly directed to nuclear antigens including DNA, histones, nucleoproteins, RNA among others [43].

\subsection{Novel Therapeutic Options in SLE}

A study was carried out to investigate whether an increase in vitamin D levels in SLE patients was associated with improvement in disease activity. To estimate the association between levels of 25(OH) D and various measures of disease activity longitudinal regression models were used. It was found that a $20-\mathrm{ng} / \mathrm{ml}$ increase in the $25(\mathrm{OH}) \mathrm{D}$ level was associated with a $21 \%$ decrease in the odds of having a high disease activity score and a $15 \%$ decrease in the odds of having clinically important proteinuria [41,44]. Another avenue for immunotherapy is the generation of stable tolerogenic DCs that are able to induce and maintain regulatory $\mathrm{T}$ cell homeostasis in vivo [45]. T cell tolerance can be achieved by tolerogenic DCs, which have the capacity of blocking undesired autoimmune responses. Several molecules are expressed on DCs including TLRs, CD86, PDL-1 and Fc $\gamma$ Rs which play a role in the innate and specific acquired immune responses [46].

A new monoclonal antibody promises to be an effective immunotherapy in SLE patients; its name is Epratuzumab, a humanized monoclonal antibody, which targets CD22 on B cells. It acts as B cell modulators, inhibiting signalling pathways of the B cell receptor. It has been shown to be efficacious in open-label and Phase I and Phase II randomized controlled trials $[47,48]$. In addition many purified intravenous immunoglobulins (IVIg) have been produced and they have been effective in the treatment of patients with SLE [49,50,51,52]. IVIg has been used due to its anti-inflammatory properties in recognized autoimmune disorders that include idiopathic thrombocytopenic purpura (ITP), Kawasaki disease, Guillain-Barré syndrome and other autoimmune neuropathies, myasthenia gravis, dermatomyositis and several rare inflammatory diseases [53].

There is not a consensus in the pharmacological effects of this therapy. We has published three cases of SLE which were consequently treated with a commercial IVIg named Intacglobin and all three cases were free of flares during the period of the treatment that was 1 year. We hypothesize that the immune-suppressing activity of IVIg may be due to its capacity to inhibit the production of autoantibodies, probably by blocking immunoglobulin receptors on B cells. The IVIg therapy contains opsonins, which may improve the phagocytosis of immunocomplexes by antigen-presenting cells [49,54]. In addition, IVIg can be given to patients with hypogammaglobulinemia-associated SLE [55] and also to patients with infections due to its polyclonal antibody overload against many microorganisms. IVIg causes neutralization and IgG-complement mediated lysis [56].

Some of the treatment strategies have focused on blocking IFN $\alpha$ or its receptor and others the plasmacytoid dendritic cell (pDC), which is the principal IFN $\alpha$ producing cell [57]. Rituximab is a monoclonal antibody, which specifically depletes B lymphocytes and it has been used successfully in the management of steroid-resistant autoimmune thrombocytopenia [58] and childhood-onset SLE [59]. When rituximab is administrated at an earlier stage, it prevents irreversible vital organ damage [60].

\section{Conclusion}

When we look at SLE we are seen the iceberg's pick, so it is very important to have in mind the several triggers that can cause this disease for a prompt diagnosis specially when it occurs in ethnic groups with low SLE prevalence. Fortunately today we have a number of therapies that are available to treat this rheumatic disorder, for example IVIg and Rituximab together with much traditional treatment including steroids. However, SLE hides behind other rheumatic or inflammatory disorders and constitutes a professional challenge to us. Several new drugs for SLE have shown to be efficacious in open-label and Phase I 
and Phase II randomized controlled trials, which represented advancement in medical sciences.

\section{Competing Interests}

The authors declare that no competing interests exist.

\section{References}

[1] Pisetsky, D.S., Buyon, J.P. and Manzi, S., Chapter 17. "Systemic lupus erythematosus”. In: Klippel, J.H., Crofford, L.J., Stone, J.H. and Weyand, C.M., Primer on the Rheumatic Diseases. Edition 12. Arthritis Foundation, Atlanta, GA., 2001.

[2] Rus, V., Hajeer, A. and Hochberg, M.C., Chapter 7. "Systemic lupus erythematosus”. In: Silman, A.J. and Hochberg, M.C., (eds.) Epidemiology of the Rheumatic Disease. 2nd edition. Oxford University Press, New York, 2001.

[3] Lawrence, R.C., Felson, D.T., Helmick, C.G., Arnold, L.M., Choi, H., Deyo, R.A., Gabriel, S., Hirsch, R., Hochberg, M.C., Hunder, G.G., Jordan, J.M., Katz, J.N., Maradit Kremers, H. and Wolfe, F. for the National Arthritis Data Workgroup. "Estimates of the prevalence of arthritis and other rheumatic conditions in the United States: Part II”, Arthritis Rheum, 58 (1). 26-35. Jan. 2008.

[4] Helmick, C.G., Felson, D.T., Lawrence, R.C., Gabriel, S., Hirsch, R., Kwoh, C.K., Liang, M.H., Maradit Kremers, H., Mayes, M.D., Merkel, P.A., Pillemer, S.R., Reveille, J.D. and Stone, J.H., for the National Arthritis Data Workgroup. "Estimates of the prevalence of arthritis and other rheumatic conditions in the United States: Part I", Arthritis Rheum, 58 (1). 15-25. Jan. 2008.

[5] Lawrence, R.C., Helmick, C.G., Arnett, F.C., Deyo, R.A., Felson, D.T., Giannini, E.H., Heyse, S.P., Hirsch, R., Hochberg, M.C., Hunder, G.G., Liang, M.H., Pillemer, S.R., Steen, V.D. and Wolfe, F., "Estimates of the prevalence of arthritis and selected musculoskeletal disorders in the United States”, Arthritis Rheum, 41 (5). 778-799. May. 1998.

[6] Chakravarty, E.F., Bush, T.M., Manzi, S., Clarke, A.E. and Ward, M.M., "Prevalence of adult systemic lupus erythematosus in California and Pennsylvania in 2000: estimates obtained using hospitalization data”, Arthritis Rheum, 56 (6). 2092-2094. Jun. 2007.

[7] Pons-Estel, G.J., Alarcón, G.S., Scofield, L., Reinlib, L. and Cooper, G.S., "Understanding the epidemiology and progression of systemic lupus erythematosus”. Semin Arthritis Rheum, 39 (4). 257-268. Feb. 2010.

[8] Uramoto, K.M., Michet, C.J. Jr., Thumboo, J., Sunku, J., O'Fallon, W.M., Gabriel, S.E., "Trends in the incidence and mortality of systemic lupus erythematosus, 1950-1992”. Arthritis Rheum, 42 (1). 46-50. Jan. 1999.

[9] Danchenko, N., Satia, J.A. and Anthony, M.S., "Epidemiology of systemic lupus erythematosus: a comparison of worldwide disease burden”, Lupus, 15 (5). 308-318. 2006.

[10] Rus, V., Maury, E.E. and Hochberg, M.C, "The epidemiology of systemic lupus erythematosus”. In: Dubois' Lupus Erythematosus, Wallace DJ, Hahn BH (Eds), Lippincott Williams and Wilkins, Philadelphia 2002.

[11] Peschken, C.A. and Esdaile, J.M., "Rheumatic diseases in North America's indigenous peoples”, Semin Arthritis Rheum, 28 (6). 368-391. Jun. 1999.

[12] Petri, M., "Epidemiology of systemic lupus erythematosus”, Best Pract Res Clin Rheumatol, 16 (5). 847-858. Dec. 2002.

[13] Hochberg, MC., The incidence of systemic lupus erythematosus in Baltimore, Maryland, 1970-1977, Arthritis Rheum, 28 (1). 80-86. Jan. 1985..

[14] Serdula, M.K. and Rhoads, G.G., "Frequency of systemic lupus erythematosus in different ethnic groups in Hawaii”, Arthritis Rheum, 22 (4). 328-233. Apr. 1979.

[15] Symmons, D.P., "Frequency of lupus in people of African origin", Lupus, 4 (3). 176-178. Jun. 1995.

[16] Hart, H.H., Grigor, R.R. and Caughey, D.E., Ethnic difference in the prevalence of systemic lupus erythematosus, Ann Rheum Dis, 42 (5). 529-532. Oct. 1983.

[17] Chung, S.A., Tian, C., Taylor, K.E., Lee, A.T., Ortmann, W.A., Hom, G., Graham, R.R., Nititham, J., Kelly, J.A., Morrisey, J., Wu, H., Yin, H., Alarcón-Riquelme, M.E., Tsao, B.P., Harley, J.B.,
Gaffney, P.M., Moser, K.L., Manzi, S., Petri, M., Gregersen, P.K., Langefeld, C.D., Behrens, T.W., Seldin, M.F. and Criswell, L.A., "European population substructure is associated with mucocutaneous manifestations and autoantibody production in systemic lupus erythematosus”, Arthritis Rheum, 60 (8). 24482456. Aug. 2009.

[18] Cooper, G.S., Dooley, M.A., Treadwell, E.L., St Clair, E.W., Parks, C.G. and Gilkeson, G.S., "Hormonal, environmental, and infectious risk factors for developing systemic lupus erythematosus”, Arthritis Rheum, 41 (10). 1714-1724. Oct. 1998.

[19] Costenbader, K.H., Feskanich, D., Stampfer, M.J. and Karlson, E.W., "Reproductive and menopausal factors and risk of systemic lupus erythematosus in women”, Arthritis Rheum, 56 (4). 12511262. Apr. 2007.

[20] Lahita, R.G., "The role of sex hormones in systemic lupus erythematosus", Curr Opin Rheumatol, 11 (5). 352-356. Sep. 1999.

[21] Uramoto, K.M., Michet, C.J. Jr., Thumboo, J., Sunku, J., O'Fallon, W.M. and Gabriel, S.E., "Trends in the incidence and mortality of systemic lupus erythematosus, 1950-1992”. Arthritis Rheum, 42 (1). 46-50. Jan. 1999.

[22] Sacks, J.J., Helmick, C.G. and Langmaid, G., "Deaths from arthritis and other rheumatic conditions, United States, 19791998”, J Rheumatol, 31(9). 1823-1828. Sep. 2004.

[23] Biswas, P.S., Kang, K., Gupta, S., Bhagat, G. and Pernis, A.B., “A murine autoimmune model of rheumatoid arthritis and systemic lupus erythematosus associated with deregulated production of IL17 and IL-21", Methods Mol Biol, 900. 233-251. 2012.

[24] Pawlak, C.R., Witte, T., Heiken, H., Hundt, M., Schubert, J., Wiese, B., Bischoff-Renken, A., Gerber, K., Licht, B., Goebel, M.U., Heijnen, C.J., Schmidt, R.E. and Schedlowski, M., "Flares in patients with systemic lupus erythematosus are associated with daily psychological stress", Psychother Psychosom, 72 (3). 159165. May-Jun. 2003.

[25] Williams, E.M., Penfield, M., Kamen, D. and Oates, J.C., “An Intervention to Reduce Psychosocial and Biological Indicators of Stress in African American Lupus Patients: The Balancing Lupus Experiences with Stress Strategies Study”, Open J Prev Med, 4 (1). 22-31. Jan. 2014.

[26] Williams, D.R., "The health of men: structured inequalities and opportunities”, Am J Public Health, 93 (5). 724-731. May. 2003.

[27] Arkema, E.V. and Simard, J.F., "Perinatal risk factors for future SLE: a population-based nested case-control study”, Lupus, 10. Feb. 2015. [Epub ahead of print]

[28] Simard, J.F., Karlson, E.W., Costenbader, K.H., Hernán, M.A., Stampfer, M.J., Liang, M.H. and Mittleman, M.A., "Perinatal factors and adult-onset lupus”, Arthritis Rheum, 59 (8). 1155-1161. Aug. 2008.

[29] 29. Gilbert, E.L. and Ryan, M.J., "Estrogen in cardiovascular disease during systemic lupus erythematosus”, Clin Ther, 36 (12). 1901-1912. Dec. 2014.

[30] Rojas-Villarraga, A., Torres-Gonzalez, J.V. and Ruiz-Sternberg, A.M., "Safety of Hormonal Replacement Therapy and Oral Contraceptives in Systemic Lupus Erythematosus: A Systematic Review and Meta-Analysis”, PLoS One, 9 (8). Aug. 2014.

[31] Quintero, O.L., Amador-Patarroyo, M.J., Montoya-Ortiz, G., Rojas-Villarraga, A. and Anaya, J.M., "Autoimmune disease and gender: plausible mechanisms for the female predominance of autoimmunity”, J Autoimmun, 38 (2-3). 109-119. May. 2012.

[32] Schwarz, E.B. and Lohr, P.A., "Oral contraceptives in women with systemic lupus erythematosus”, N Engl J Med, 354 (11). 1203-1204. Mar. 2006.

[33] Carvalho, C., Marinho, A., Leal, B., Bettencourt, A., Boleixa, D., Almeida, I., Farinha, F., Costa, P.P., Vasconcelos, C. and Silva, B.M., "Association between vitamin D receptor (VDR) gene polymorphisms and systemic lupus erythematosus in Portuguese patients”, Lupus, Feb 6. 2015. [Epub ahead of print]

[34] Anselm, M. and Sen Hee, T., "Environmental Factors, Toxicants and Systemic Lupus Erythematosus”, Int J Mol Sci, 15 (9). 1604316056. Sep. 2014.

[35] Hewagama, A. and Richardson, B., "The genetics and epigenetics of autoimmune diseases”, J Autoimmun, 33 (1). 3-11. Aug. 2009.

[36] Lisnevskaia, L., Murphy, G. and Isenberg, D., "Systemic lupus erythematosus”, Lancet, 384 (9957). 1878-1888. Nov. 2014.

[37] Bijl, M. and Kallenberg, C.G., "Ultraviolet light and cutaneous lupus”, Lupus, 15 (11). 724-727. Nov. 2006.

[38] Somers, E.C. and Richardson, B.C., "Environmental exposures, epigenetic changes and the risk of lupus", Lupus, 23 (6). 568-576. May. 2014. 
[39] Piotrowski, P., Wudarski, M., Sowińska, A., Olesińska, M. and Jagodzinski, P.P., "TNF-308 G/A polymorphism and risk of systemic lupus erythematosus in the Polish population”, Mod Rheumatol, 9. 1-20. Feb. 2015. [Epub ahead of print]

[40] da Silva Fonseca, A.M., de Azevedo Silva, J., Pancotto, J.A. Donadi, E.A., Segat, L., Crovella, S. and Sandrin-Garcia, P., "Polymorphisms in STK17A gene are associated with systemic lupus erythematosus and its clinical manifestations”, Gene, 527 (2). 435-439. Sep. 2013.

[41] Ben-Zvi, I., Aranow, C., Mackay, M., Stanevsky, A., Kamen, D.L., Marinescu, L.M., Collins, C.E., Gilkeson, G.S., Diamond, B. Hardin, J.A., "The impact of vitamin D on dendritic cell function in patients with systemic lupus erythematosus”, PLoS One, 5 (2) Feb. 2010.

[42] Hou, Y., Zhang, C., Xu, D. and Sun, H., "Association of KIR and HLA-Cw genes combinations with systemic lupus erythematosus", Clin Exp Immunol, Jan. 2015. [Epub ahead of print]

[43] Fenton, K., "The effect of cell death in the initiation of lupus nephritis”, Clin Exp Immunol, 179 (1). 11-16. Jan. 2015.

[44] Petri, M., Bello, K.J., Fang, H. and Magder, L.S., "Vitamin D in systemic lupus erythematosus: modest association with disease activity and the urine protein-to-creatinine ratio", Arthritis Rheum, 65 (7). 1865-1871. Jul. 2013.

[45] Mok, M.Y., "Tolerogenic dendritic cells: role and therapeutic implications in systemic lupus erythematosus”, Int J Rheum Dis, Dec. 2014. [Epub ahead of print]

[46] Mackern-Oberti, J.P., Llanos, C., Vega, F., Salazar-Onfray, F., Riedel, C.A., Bueno, S.M. and Kalergis, A.M., "Role of dendritic cells in the initiation, progress and modulation of systemic autoimmune diseases”, Autoimmun Rev, 14 (2). 127-139. Feb. 2015.

[47] Rao, V. and Gordon, C., "Evaluation of epratuzumab as a biologic therapy in systemic lupus erythematosus", Immunotherapy, 6 (11). 1165-1175. Nov. 2014.

[48] Wallace, D.J., Gordon, C., Strand, V., Hobbs, K., Petri, M., Kalunian, K., Houssiau, F., Tak, P.P., Isenberg, D.A., Kelley, L., Kilgallen, B., Barry, A.N., Wegener, W.A. and Goldenberg, D.M., "Efficacy and safety of epratuzumab in patients with moderate/severe flaring systemic lupus erythematosus: results from two randomized, double-blind, placebo-controlled, multicentre studies (ALLEVIATE) and follow-up”, Rheumatology (Oxford), 52 (7). 1313-1322. Jul. 2013.

[49] Sakthiswary, R. and D'Cruz, D., "Intravenous immunoglobulin in the therapeutic armamentarium of systemic lupus erythematosus: a systematic review and meta-analysis”, Medicine (Baltimore), 93 (16). e86. Oct. 2014.

[50] Mulhearn, B. and Bruce, I.N., "Indications for IVIG in rheumatic diseases", Rheumatology (Oxford), Nov. 2014. [Epub ahead of print]

[51] Qian, J., Wang, L., Yuan, X., Wang, L. and Chen, T., "Doserelated regulatory effect of intravenous immunoglobulin on dendritic cells-mediated immune response”, Immunopharmacol Immunotoxicol, 36 (1). 33-42. Feb. 2014.

[52] Camara, I., Sciascia, S., Simoes, J., Pazzola, G., Salas, V., Karim, Y., Roccatello, D. and Cuadrado, M.J., "Treatment with intravenous immunoglobulins in systemic lupus erythematosus: a series of 52 patients from a single centre”, Clin Exp Rheumatol, 32 (1). 41-47. Jan-Feb. 2014.

[53] Hartung, H.P., Mouthon, L., Ahmed, R., Jordan, S., Laupland, K.B. and Jolles, S., "Clinical applications of intravenous immunoglobulins (IVIg)--beyond immunodeficiencies and neurology”, Clin Exp Immunol, 158 Suppl 1. 23-33. Dec. 2009.

[54] Justiz Vaillant, A.A., Ramirez, N., Cadiz, A. and Akpaka, P.E., "Case Reports on the Use of Intravenous Immunoglobulins (IVIG) in the Treatment of Systemic Lupus Erythematosus (SLE)”, J Clin Case Rep, 3. 263. 2013.

[55] Lim, E., Tao, Y., White, A.J., French, A.R. and Cooper, M.A., "Hypogammaglobulinemia in pediatric systemic lupus erythematosus”, Lupus, 22 (13). 1382-1387. Nov. 2013.

[56] Sciascia, S., Cuadrado, M.J. and Karim, M.Y.., "Management of infection in systemic lupus erythematosus", Best Pract Res Clin Rheumatol, 27 (3). 377-389. Jun. 2013.

[57] Kirou, K.A. and Gkrouzman, E., "Anti-interferon alpha treatment in SLE”, Clin Immunol, 148 (3). 303-312. Sep. 2013.

[58] Sardesai, V.V., Sardesai, V.R. and Agarwal, T.D., "Steroidresistant autoimmune thrombocytopenia in systemic lupus erythematosus treated with rituximab”, Indian J Dermatol, 60 (1). 106. Jan-Feb. 2015.

[59] Tambralli, A., Beukelman, T., Cron, R.Q. and Stoll, M.L., "Safety and Efficacy of Rituximab in Childhood-onset Systemic Lupus Erythematosus and Other Rheumatic Diseases”, J Rheumatol, Jan. 2015. [Epub ahead of print]

[60] Braun-Moscovici, Y., Butbul-Aviel, Y., Guralnik, L., Toledano, K., Markovits, D., Rozin, A., Nahir, M.A. and Balbir-Gurman, A., "Rituximab: rescue therapy in life-threatening complications or refractory autoimmune diseases: a single center experience", Rheumatol Int, 33 (6). 1495-1504. Jun. 2013. 